University of Nebraska - Lincoln

DigitalCommons@University of Nebraska - Lincoln

Educational Psychology Papers and

Publications

Educational Psychology, Department of

June 2002

\title{
Assessing the Social Context in Initial Conjoint Behavioral \\ Consultation Interviews: An Exploratory Analysis Investigating \\ Processes and Outcomes
}

\author{
Susan M. Sheridan \\ University of Nebraska-Lincoln, ssheridan2@unl.edu \\ Sean P. Meegan \\ Western Illinois University \\ John W. Eagle \\ University of Nebraska-Lincoln
}

Follow this and additional works at: https://digitalcommons.unl.edu/edpsychpapers

Part of the Educational Psychology Commons

Sheridan, Susan M.; Meegan, Sean P.; and Eagle, John W., "Assessing the Social Context in Initial Conjoint Behavioral Consultation Interviews: An Exploratory Analysis Investigating Processes and Outcomes" (2002). Educational Psychology Papers and Publications. 12.

https://digitalcommons.unl.edu/edpsychpapers/12

This Article is brought to you for free and open access by the Educational Psychology, Department of at DigitalCommons@University of Nebraska - Lincoln. It has been accepted for inclusion in Educational Psychology Papers and Publications by an authorized administrator of DigitalCommons@University of Nebraska - Lincoln. 


\title{
Assessing the Social Context in Initial Conjoint Behavioral Consultation Interviews: An Exploratory Analysis Investigating Processes and Outcomes
}

\author{
Susan M. Sheridan \\ University of Nebraska-Lincoln \\ Sean P. Meegan \\ Western Illinois University \\ John W. Eagle \\ University of Nebraska-Lincoln
}

\begin{abstract}
In this exploratory study, the communicative process in conjoint behavioral consultation was investigated with a coding system designed to measure two dimensions of communication (i.e., influence and involvement). The nature of discrete speech acts that typify consultants' and consultees' behaviors in $\mathrm{CBC}$ (i.e., collaborative, controlling, obliging, withdrawing) and the communicative function of speech exchanges within $\mathrm{CBC}$ (i.e., affiliation, distancing, mixed) were investigated. An initial exploration of the relationship between speech exchanges and direct and indirect outcomes in CBC was conducted. Results indicated that $\mathrm{CBC}$ meetings were characterized by a high degree of affiliation among participants; however, few significant relationships were identified between the exchanges and outcomes. Future research is recommended to address limitations of the present study and to advance the field's understanding of how communication patterns in CBC may facilitate positive case outcomes.
\end{abstract}

Collaboration in consultation is an area that has received a great deal of scrutiny in recent years. Criticisms of collaboration revolve around several core assumptions of behavioral consultation, including (a) the respective roles of consultants, parents, and teachers; (b) the most effective interactional styles among consultation

This study was supported by federal grants awarded to the first author by the U. S. Department of Education, Office of Special Education Programs. The opinions herein reflect those of the authors and do not reflect opinion or policy of the funding agency.

Correspondence: Susan M. Sheridan, University of Nebraska-Lincoln, Department of Educational Psychology, 239 Teachers College Hall, Lincoln, NE 68588-0345; E-mail: ssheridan2@ unl.edu.

The action editor for publication in School Psychology Quarterly was Terry B. Gutkin. This article was accepted for publication May 20, 2002. 
participants; and (c) the extent to which collaborative interactions facilitate effective behavioral intervention strategies (Noell \& Witt, 1996; Witt, Gresham, \& Noell, 1996). The "collaboration debate," fueled initially by a study by Witt (1990), sparked research investigating relational interaction patterns in behavioral consultation. ${ }^{1}$ However, problems inherent in the research include lack of a clearly defined collaboration construct and little to no link to behavioral outcomes.

Historically, proponents of collaboration in consultation have highlighted the importance of active and reciprocal roles of consultants and consultees (e.g., teachers, parents) within consultation settings (Gutkin \& Curtis, 1982). This line of thinking holds that all participants in consultation bring with them particular relationship histories with the target child, unique opportunities for observation and intervention, and important information of value to consultation. In the last decade, however, critics have questioned the utility of collaborative relationships within educational consultation practice (Noell \& Witt, 1996; Witt, 1990). These alternative conceptualizations, based on analysis of individual speech acts in consultation, purport a directive, prescriptive role for the consultant who independently orchestrates and commands intervention strategies.

A central problem in the debate over the merits of collaboration within consultation surrounds the lack of a clearly defined collaboration construct. This issue was articulated clearly in previous writings (Kratochwill, 1991; Sheridan, 1992); however, researchers have not heeded the call for the development of a careful definition of collaboration. A standard definition of collaboration may be found in Webster's dictionary, where the verb collaborate is defined as "to work jointly with others ... to cooperate" (Webster, 1981, p. 217). Educational and psychological definitions generally characterize collaboration as an interdependent style of interaction where participants work together toward common goals (Friend \& Cook, 1992; Rogoff, 1998; Welch \& Sheridan, 1995). Importantly, collaboration is predicated on an inherently joint, interpersonal dynamic and interactive process. Although independent speech units made by individual participants (including those whose intent and function are to promote collaboration) provide information about discrete statements, the relational context of consultation requires analyses of reciprocal exchanges.

Conceptual and methodological problems plague previous attempts to examine collaboration in consultation settings. Coding systems have been used in the absence of a direct theoretical link between the operational codes and an underlying conceptual definition of collaboration. The various coding systems used in previous studies (Folger \& Puck, 1976; Rogers \& Farace, 1975; Tracey \& Ray, 1984) measure seemingly related constructs, but may actually contain little more than face validity for studying collaboration. Constructs such as "domineering," "dominant," and "submissive" exchanges (Folger \& Puck, 1976; Rogers \& Farace,

\footnotetext{
${ }^{1}$ A comprehensive review of the "collaboration debate" in consultation is available in Gutkin (1999), and will therefore not be reviewed here. Readers interested in obtaining a thorough review and analysis of the literature should refer to this excellent source.
} 
1975); "topic determination/topic continuation" patterns (Tracey \& Ray, 1984) and "one-up" and "one-down" speech acts (Rogers \& Farace, 1975) have been the focus of consultation-based relational communication studies. These constructs define verbal activity of the participants but do not characterize the conversational intent of the interactants.

There has been a tendency in consultation research to define collaboration in terms of what it is not. If consultants are dominant, if they successfully determine topics of conversation, or if they demonstrate control by eliciting information, they are "not collaborative" (i.e., they are acting in a noncollaborative way). Gutkin (1999) has questioned whether processes such as topic determination, making bids (Tracey \& Ray, 1984), and dominance (Rogers \& Farace, 1975) are indeed contraindications of collaboration. Specifically, there appears to be no evidence that the existence of communicative behaviors such as dominance, topic determination, or control in consultation settings necessarily precludes the possibility of collaboration (Gutkin, 1999). In the present study, we directly address the extent to which communicative strategies akin to dominance and control are component processes within collaborative consultation settings.

In addition, few have questioned the construct validity of the various coding systems in the consultation context, and little attention has been paid to regulatory processes involved in maintaining and enhancing social relationships during consultation. In practice, consultation represents a more complex task than simply guiding a problem-solving process. It also requires maintenance of interpersonal relationships as individuals work together to achieve a common goal. This relational task is particularly relevant in conjoint behavioral consultation, which focuses on strengthening interpersonal relationships and constructive partnerships between parents and school personnel (Sheridan, Kratochwill, \& Bergan, 1996).

Constructs in this study have been drawn from multiple literatures (e.g., consultation, collaborative problem solving, stress and coping, and life task pursuit) to provide a stronger theoretical base to the investigation of communication strategies and collaboration within consultation. Researchers investigating collaborative problem solving across the life span consistently highlight the importance of direct, active, and mutual participation of group members (Azmitia, 1996; Berg, Meegan, \& Deviney, 1998; Johnson, Maruyama, Johnson, Nelson, \& Skon, 1981; Rogoff, 1998). The benefits of such collaborative problem-solving styles have been reported in multiple domains (Meegan \& Berg, 2002) and we extend that literature to the study of outcomes in conjoint behavioral consultation (CBC). The mechanism of the success of collaborative styles of interaction in $\mathrm{CBC}$ lies in the balance between focusing on and progressing through task-related activities and establishing and maintaining positive social relations among participants (Nakamura \& Finck, 1980; Sheridan et al., 1996; Strough, Berg, \& Meegan, 2001).

It is our contention that both task and relational goals are common to consultation, and in particular, CBC. Task demands include those related to identifying, assessing, and addressing behavioral, social-emotional, or academic problems using 
structured, validated problem-solving strategies. Decades of research has indicated that effective problem-solving process is important (Bergan \& Tombari, 1976; Fuchs \& Fuchs, 1989) and that behavioral consultation and its variants promote effective interventions and outcomes (McLeod, Jones, Somers, \& Havey, 2001; Sheridan, Welch, \& Orme, 1996). Relational goals are those concerned with maintaining open, cooperative interactions among participants. In general, research has shown that consultees (i.e., teachers) favor collaborative approaches to consultation over those that are highly prescriptive (Babcock \& Pryzwansky, 1983; Gutkin, 1980; Maitland, Fine, \& Tracy, 1985). Significant negative relationships have been found between teacher ratings of satisfaction and consultant use of closed questions (Hughes \& DeForest, 1993), and pure dominant bids by consultants (Erchul, Covington, Hughes, \& Meyers, 1995).

Many studies have investigated the task-related strategies and outcomes of behavioral consultation (BC) and CBC (Busse, Kratochwill, \& Elliott, 1999; Sheridan, Eagle, Cowan, \& Mickelson, 2001). The focus of the present study concerns the relational aspect of $\mathrm{CBC}$, with emphasis on the social context created through the interactions among consultation participants. Consultative problem solving represents a broad class of situations in which both social (i.e., initiating and maintaining interpersonal relationships) and task aspects (i.e., problem identification, problem analysis, plan implementation, plan evaluation) must be negotiated simultaneously by consultation team members. The coding system used (Leaper, 1991) reflects two of the major functions served by interactions within a consultation group: to influence the task at hand while simultaneously establishing or maintaining social involvement within the group. The system comprises four codes reflecting collaborative, controlling, obliging, and withdrawing speech acts. Interactions of these codes among participants yield one of three possible patterns of exchange: affiliative, distancing, and mixed.

The approach to interactions used in this study focuses on sequences of interactions among consultation participants, allowing for the identification of the social context created among consultants and consultees as consisting of conversational processes, rather than only broad categories of statements. Analysis of exchanges among participants in consultation takes into account both when and how often speech acts occur by exploring their sequential patterning. This is central to the consultation process given its presumed bidirectional nature. The reciprocal aspect of consultation (including consultation with parents and teachers as joint consultees) requires investigation of the exchanges across individuals, in addition to frequencies of discrete, independent speech acts by participants. Importantly, speech acts may have different functions depending on what precedes and follows them. For example, in the present analyses using the Psychosocial Process Coding Scheme (PPCS; Leaper, 1991), obliging speech acts that "go along with" another's suggestion have different functions depending on whether they are preceded by controlling or collaborative statements. A simple statement such as "OK" is interpreted very differently if preceded by "Do this now" (suggesting a domineering, 
submissive interactional pattern) versus "Should we go forward with this?" (indicative of an affiliative, cooperative interactional pattern). ${ }^{2}$ It is the speech act exchanges that set the affective tone for the $\mathrm{CBC}$ interactions.

An additional problem in the debate over the merits of collaboration within consultation surrounds the manner in which outcomes have been defined. Specifically, consultees' perceptions and satisfaction with the consultant using subjective, paper-and-pencil instruments (e.g., the Consultant Evaluation Form; Erchul, 1987) defines the dependent variable in most studies. Certainly consultees' perceptions of what is acceptable are important; however, they are limited in scope and objectivity. Only one study to date (Busse, Kratochwill, \& Elliott, 1999) has investigated consultation communication processes in relation to objective, direct outcome measures. This study represents an advance over previous process research given (a) its use of a coding system specifically developed for use in consultation (Consultation Analysis Record; Bergan \& Tombari, 1975) and (b) its inclusion of single-subject effect sizes as one dependent measure. However, this study did not attempt to study collaborative acts and does not further conceptual understanding of this construct in consultation. The purpose of the present study is to explore the presence of a collaborative, affiliative context in consultation and its relationship to case outcomes measured both directly and indirectly, using objective and subjective means.

The type of consultation used in this study was $\mathrm{CBC}$, an extension of behavioral consultation where parents and teachers are brought together to address concerns about a child, with the assistance of a consultant (Sheridan, Salmon, Kratochwill, \& Carrington Rotto, 1992). Content goals of CBC include defining and addressing target behavioral, social, or academic concerns. These have been explored in previous research with positive outcomes (Colton \& Sheridan, 1998; Galloway \& Sheridan, 1994; Sheridan, Kratochwill, \& Elliott, 1990; Weiner, Sheridan, \& Jenson, 1998). Likewise, there are several CBC goals associated with relational issues, all of which seem to necessitate collaboration between home and school systems (i.e., parents and educators; Sheridan et al., 1996). Process goals include (a) improving the relationship between the child, family, and school personnel; (b) establishing home-school partnerships; (c) promoting shared ownership for identified problems and solutions; and (d) establishing shared educational goals for a child. To accomplish these goals, problems and solutions are co-constructed via active participation by teachers, parents, and consultants. The relationship between home and school and the identification of unique but necessary roles among participants in enhancing educational outcomes for children are paramount.

The purposes of this study were to extend the understanding of communication

\footnotetext{
${ }^{2}$ Given that speech act exchanges are composed of speech acts among participants, individual acts are also worthy of report. However, in the current study, individual speech acts are reported in a descriptive manner only; they are not subjected to further analysis.
} 
strategies and relational conditions within the consultation (i.e., CBC) context. Specifically, our interest was to explore the communicative process in CBC with a coding system designed to measure two dimensions of communication in $\mathrm{CBC}$ (i.e., influence and involvement). First, we were interested in identifying the nature of speech acts that typify consultants' and consultees' behaviors in CBC (i.e., collaborative, controlling, obliging, withdrawing). Given a coding system sensitive to collaborative speech acts, the communicative function of exchanges within CBC (i.e., affiliative, distancing, mixed) was also investigated. Finally, an initial exploration of the relationship between communicative exchanges and direct and indirect outcomes in $\mathrm{CBC}$ was conducted. It was expected that the relationship between affiliative exchanges and both objective and subjective case outcomes would be positive (Babcock \& Pryzwansky, 1983; Erchul et al., 1995; Hughes \& DeForest, 1993).

\section{METHOD}

\section{Participants}

Participants in this study were 13 consultants who were part of a larger CBC training and research project. Consultants were graduate students in school psychology who were involved in learning the principles and procedures of $\mathrm{CBC}$ and using them in school settings. A total of 11 consultants were female and 2 were male; all were Caucasian. The mean age was 30.58 years (range $=23$ to 53). A total of 7 had a Bachelor's degree as their highest educational degree; 6 had a Master's degree.

Consultees were 19 teachers and 19 parents of students with identified disabilities (or at risk) who were being served in general education classrooms for a majority of their instructional time. In most cases, triads (one consultant, one general education teacher, one parent) constituted the consultation team. In rare other cases, more than three individuals were present (e.g., both parents; more than one teacher).

A total of 16 teachers were female and 3 were male; all but one were Caucasian. The mean age of teachers was 45.85 years (range $=25$ to 55 ); the average number of years teaching was 14.19 years (range $=1$ to 30 ). A total of $83 \%$ of the teachers taught in general education classrooms; $17 \%$ were special education teachers. Half of the teachers held a Master's degree as their highest degree earned.

A total of 19 parents served as consultees in this study. Of those, 14 parents were mothers; 5 were fathers; $87 \%$ were Caucasian and $13 \%$ were non-Caucasian; $19 \%$ graduated from college.

Clients in the study were 10 students with identified disabilities and 6 students at risk of being classified in special education $(n=16)$. A total of 9 students were boys, 11 were Caucasian (3 were biracial; one was Hispanic; one was Mayan Native American), and all spoke English as their primary language. Half of the students identified for special educational services were classified with a behavioral 
disorder. Two students were learning disabled, one was intellectually impaired, and one had a diagnosis of Aspergers. One-quarter of the clients lived in families whose average annual income was $\$ 15,000$ or less. A total of $38 \%$ had only one parent living at home. Participants selected for the present analyses were from a subset of cases completed in a larger research project.

The present sample was selected based on the availability of the following data: demographic data, home or school behavioral outcome data, and subjective outcome data from forms completed at the end of consultation cases (i.e., forms that were completed in their entirety, missing no more than $15 \%$ of responses). A total of 50 cases were completed at the time of this study. Of these, $32 \%(n=16)$ met criteria for complete data sets. All of these (100\% of the 16 cases) were included in the current study.

\section{Setting}

Consultation training took place in a school psychology graduate program at a large Western university. On completing didactic training, consultation cases were completed in public schools in and around a large metropolitan area. Schools were identified by project staff as potential sites for consultation based on their verbal commitment to accept consultants and to identify students, parents, and teachers interested in becoming involved in consultation. All consultation interviews were completed in the general education classroom of students for whom CBC services were solicited.

\section{Instruments and Dependent Variables}

The primary instrument used in this study was the Psychosocial Processes Coding Scheme (PPCS) developed by Leaper (1991). Dependent variables included (a) child behaviors measured via direct observations; (b) perceived effectiveness of consultation procedures, measured with the Behavioral Intervention Rating ScaleRevised, Effectiveness factor (BIRS; Von Brock \& Elliott, 1987) and Goal Attainment Scaling (Kirusek, Smith, \& Cardillo, 1994); (c) acceptability of the consultation procedures (measured with the BIRS, Acceptability factor (Von Brock \& Elliott, 1987); and (d) satisfaction with the consultant measured via the Consultant Evaluation Form (CEF; Erchul, 1987).

Communication strategies coding scheme. The Psychosocial Processes Coding Scheme (PPCS; Leaper, 1991) is a communication strategies coding system that was designed to reflect the purpose or function of the speech acts used by interactants. It was selected for use in this study because of its conceptual consistency with the characteristics deemed relevant and important in consultation, and its ability to measure directly the collaboration construct. Previous research has reliably coded interpersonal processes with the PPCS to understand gender differences in children's speech (Leaper, 1991; Strough \& Berg, 2000) and adults' performance on collaborative problem-solving tasks (Berg, Johnson, Meegan, \& Strough, in press). 
TABLE 1. Communication Strategies Coding Scheme

\begin{tabular}{lll}
\hline \multirow{2}{*}{ Influence } & \multicolumn{2}{c}{ Involvement } \\
\cline { 2 - 3 } Direct & Distancing & Affiliative \\
\hline & Controlling & Collaborative \\
& Controlling the other & Mutual affirmation \\
Rejecting the other & Constructive elaboration \\
& Countering the other & Initiating joint action \\
& Resisting the other & Information exchange \\
Non-direct & Withdrawing & Obliging \\
& Evading the other & Going along with the other \\
& Delaying participation & Willing submission \\
& Reluctant submission & Seeking support \\
& Nonparticipation & \\
\hline
\end{tabular}

The system captured gender differences in communication styles consistent with theoretical propositions on developmental aspects of interpersonal processes (Maltz \& Borker, 1982; Thorne, 1993) and predicted variability in task performance consistent with theoretical propositions on collaborative cognition across the life span (Meegan \& Berg, 2001). The application of the PPCS in the present study reflects our belief that although the content of interactants' speech may vary across development and contexts (e.g., play, school, parenting, problem solving), the primary functions of speech remain (i.e., influence, involvement).

The PPCS captures two of the major functions served by interactions within a group. The two dimensions have often been termed influence and involvement, respectively (Leaper, 1991; see Table 1). These are qualitative, not absolute dimensions of the interaction. They reflect aspects of the tone or nature of communication. Influence refers to the degree to which a speech act attempts to control the task in consultation, or the extent that a message either directly or indirectly influences consultation (i.e., with assertive or passive messages). Influence reflects the intent of the speaker to either assert the self and influence the other person (direct) or downplay the self and not directly influence the other (nondirect). ${ }^{3}$ Involvement refers to the degree to which a speech act facilitates or hinders the social relation-

${ }^{3}$ The dimensions of "direct" and "nondirect" influence in this coding scheme are similar to but slightly different than those suggested by Gutkin (1999). Specifically, in the present system, exchanges and not individual speech acts serve the function of directing an interaction. Therefore, "collaborativeobliging" exchanges are interpreted to "direct" an interaction. The collaborative statement is directive; the obligatory statement is nondirective. Together, they suggest that participants are highly involved in preserving the relationship in an affiliative, mutually cooperative way. In Gutkin's (1999) model, this "give and take" characterizes the construct of collaboration; in this scheme, it characterizes the construct of affiliation/mutual cooperation. 
ship in consultation. Involvement reflects the intent of the speaker to either move closer to the other person (high involvement; affiliative) or to separate the speaker from the other person (low involvement; distancing). Speech acts characterized as high involvement reflect efforts at maintaining involvement in the social relationship. Thus, involvement is not synonymous with level of participation.

The two levels of the two dimensions create four main categories of speech acts. Collaborative speech acts are high on both influence and involvement; they directly influence the consultation exchange and they are affiliative in nature. Collaborative speech acts include (a) instances of mutual affirmation (e.g., "I think you're doing a good job in the classroom"), (b) constructive elaboration (e.g., "I've often had that problem at home"), (c) initiations of joint activity(e.g., "Let's focus on her academic problems right now"), and (d) exchanges of information (e.g., "She's quite willing to cooperate"). Controlling speech acts are high on influence and low on involvement; they, too, directly influence the interaction, however, they serve to cause distance among participants in consultation. These speech acts include statements that are (a) controlling (e.g., "Stop giving in to him when he makes those demands"), (b) countering (e.g., "That's not right"), (c) rejecting (e.g., "This meeting won't accomplish anything good"), or (d) resisting others (e.g., "Why not?"). Obliging speech acts are low on influence and high on involvement. They do not directly influence the direction in consultation and they are intended to preserve the social relation in an affiliative way. Obliging speech acts include (a) going along with others (e.g., "Sure"), (b) willing submission (e.g., "Whichever you think is best"), or (c) seeking support (e.g., "How should I get him to do it?"). Withdrawing speech acts are low on both influence and involvement; they do not directly influence the consultation exchange, and they have the intent of distancing participants in consultation. Withdrawing speech acts include (a) evading (e.g., "I don't want to talk about it"), (b) delaying participation (e.g., "Ummm. .. . [long pause]"), (c) reluctant submission (e.g., "I don't care"), or (c) nonparticipation(e.g., silence, nonresponse).

In addition to investigating the incidence of individual speech acts, the sequential communicative exchanges between partners were of interest. Therefore, speech act exchanges were analyzed. Specifically, speech act exchanges were defined as two contiguously linked speech acts between speakers. Analysis of exchanges takes into account both when and how often speech acts occur by exploring their sequential patterning. The presumed bidirectional nature of consultation processes makes investigating conversational exchanges central to the present research.

Similar to Leaper's (1991) analyses, two types of speech act exchanges were analyzed in this study. Affiliative exchanges were characterized by mutual cooperation of both speakers and involved exchanges between speakers in which a speaker's collaborative or obliging speech act was followed by another's collaborative or obliging speech act (i.e., collaborative-collaborative, collaborativeobliging, obliging-collaborative, obliging-obliging). As an example, a consultant's statement "Let's focus on her academic problems right now" followed by a 
teacher's "OK" is representative of an affiliative exchange. Distancing exchanges were characterized by adversarial types of involvement and involved exchanges in which a speaker's controlling or withdrawing speech act was followed by another's controlling or withdrawing speech act (i.e., controlling-controlling, controlling-withdrawing, withdrawing-controlling, withdrawing-withdrawing). A consultant's "You need to use time out with Joey" followed by a parent's "I just don't know" is reflective of a distancing exchange. Mixed exchanges were characterized by interactions whereby one participant's affiliative statement was followed by the other's distancing statement, or vice versa (e.g., control-collaborate or oblige; withdraw-collaborate or oblige; collaborate-control or withdraw; oblige-control or withdraw). An example of a mixed exchange is a teacher's controlling comment "You need to tell him that he can't do that at home," followed by a collaborative statement made by the consultant, such as "Would you mind if we discuss that a little later when we discuss plan development?" Inaudible exchanges were those for which one or both speech acts were not able to be coded due to difficulties ascertaining the content of the statement. Approximately $2 \%$ of all speech acts and $6 \%$ of speech act exchanges were coded inaudible. A proportion of each type of sequence was created for each group based on the total number of conversational exchanges between group members.

Direct observations of behavior change. Direct observations of clients' (i.e., students) target behaviors were conducted by parents and teachers. Data collection forms (i.e., Behavioral Records) were provided to consultees to (a) standardize the observational procedures; (b) provide an opportunity to train consul-tees in data collection procedures; and (c) encourage a permanent record of data. In some situations, the target behavior was defined in terms that generated a permanent product (e.g., homework completion). Direct behavioral measures were collected continuously by parents and teachers throughout all experimental phases (i.e., baseline, treatment, follow-up). Unfortunately, no reliability data are available for direct outcome measures.

Perception of efficacy. Consultees' perceptions of the efficacy of CBC in addressing the target concerns were assessed via a form of social validation known as subjective evaluation (Kazdin, 1977), which involves assessing the perceptions of behavior change and improvement of the target child by individuals in the child's natural environment. Two instruments were used to elicit consultee perceptions of outcomes. First, parents' and teachers' perceptions of CBC efficacy were assessed on a revised version of the BIRS (Von Brock \& Elliott, 1987). The BIRS consists of 24-items rated on a 6-point Likert scale. Factor analysis of the BIRS has yielded three factors: Acceptability, Effectiveness, and Time to Effect (Elliott \& Von Brock Treuting, 1991). In a study assessing the reliability and construct validity of the BIRS, Von Brock and Elliott (1987) reported a coefficients of .97 for the total scale, and $.97, .92$, and .87 for the Acceptability, Effectiveness, and Time to Effect factors, respectively. In a sample reporting on outcomes in CBC, Sheridan et al. (2001) reported a coefficients of .95 for teachers and .93 for parents, based 
on a revised version of the BIRS applicable to consultation. These researchers reported an a coefficient of .95 for the Effectiveness factor for parents and teachers, and .94 (teachers) and .86 (parents) for the Acceptability factor.

Responses to the seven items that comprise the BIRS-Effectiveness factor provided information on how parents and teachers perceived changes in the target behaviors. Parents and teachers completed the revised BIRS in its entirety at the end of the formal consultation relationship (i.e., following the final CBC interview).

Second, Goal Attainment Scaling (GAS; Kirusek et al., 1994) procedures provided a second assessment of parents' and teachers' subjective perceptions of efficacy through their rating of the degree to which consultation goals were attained. Following consultation, parents and teachers reported the degree to which they believed consultation goals were met using a scale of -2 (situation got significantly worse) to +2 (goal completely met). To simplify interpretation of the original scale, scores were transformed to a linear scale of 1 to $5(1=$ situation got worse $; 3=$ no progress made; 5 = goal completely met).

Excellent reviews of the reliability and validity of GAS procedures are available in Cardillo and Smith (1994) and Smith and Cardillo (1994), respectively. Studies that used a 5-point scale (similar to the approach used herein) reported interrater reliability indices between $r=.87$ (Kaplan \& Smith, 1977) and $r=.93$ (Schippits \& Baxter, 1978; cited in Cardillo \& Smith, 1994). Analyses of testretest reliability yielded product moment correlations of $r=.84$ over a 2- to 3week period (Woodward, Santa-Barbara, Levin, \& Epstein, 1978). There is also evidence of criterion-related (Jacobs \& Cytrynbaum, 1977) and construct validity (Johnson \& Greenberg, 1985).

Acceptability/satisfaction. Parents' and teachers' acceptability of CBC was assessed on the revised BIRS (Von Brock \& Elliott, 1987). Specifically, 15 items comprising the BIRS-Acceptability factor were used to assess consultee acceptability of CBC services.

The Consultant Evaluation Form (CEF; Erchul, 1987) was used to assess the degree of satisfaction with $\mathrm{CBC}$ services. The CEF is a 12-item, 7-point Likert scale that measures the degree to which consultees found consultants helpful. Items are scored on a 7-point scale, with 1 reflecting low satisfaction/helpfulness and 7 reflecting high satisfaction/helpfulness. Parents and teachers completed the $\mathrm{CEF}$ at the end of the formal consultation relationship (i.e., following the final $\mathrm{CBC}$ interview). Early research with the $\mathrm{CEF}$ has yielded adequate internal consistency estimates ( $r=.94$; Erchul, 1987). More recently, Sheridan et al. (2001) reported internal consistency of $r=.83$ for a teacher sample $(n=56)$ and $r=.89$ for a parent sample $(n=53)$.

\section{Procedures}

Consultation training. A criterion-based training model was used to prepare consultants to engage in structured behavioral consultation practice (Kratochwill, 
Sheridan, Carrington Rotto, \& Salmon, 1991). Specifically, consultants were part of a larger training and research project that prepared individuals to engage in consultation services with parents and teachers of students with disabilities who were being educated in general education classrooms.

Consultation training followed a model described by Sheridan et al. (1992), involving a series of advanced consultation seminars, role plays, and field-based practice with direct supervision. All consultants demonstrated mastery of CBC objectives equaling or exceeding $85 \%$ of the objectives before beginning field-based cases (assessed by supervisors and independent observers using structured CBC objective checklists; see Sheridan et al., 2001). Although it is not the intent of this study to describe the consultation training model specifically, it is noteworthy that seminar topics and supervision foci included both technical aspects of CBC (e.g., stages of consultative problem solving, objectives of $\mathrm{CBC}$ interviews) and interpersonal/relationship building skills (e.g., the use of open-ended questions, supportive statements, effective summarizations and validations).

$C B C$ cases. Following demonstrated mastery of consultation procedures, consultants were assigned to schools in a large Western city for the purpose of providing consultation services to parents and teachers of students with disabilities or who were at risk. CBC procedures were implemented following referrals made to consultants by school psychologists, teachers, or support staff in respective schools. The CBC cases followed a four-stage model, including problem identification, problem analysis, treatment implementation, and treatment evaluation (for more information on CBC procedures, see Sheridan, Kratochwill, \& Bergan, 1996). Parents and teachers were involved as joint consultees in all cases and meetings were held conjointly (with all participants present), rather than in a parallel or simultaneous manner. Most cases required four structured meetings between consultants and consultees, reflecting standard interviews for problem identification (Conjoint Problem Identification Interview; CPII), problem analysis (Conjoint Problem Analysis Interview; CPAI), treatment evaluation (Conjoint Treatment Evaluation Interview; CTEI), and a follow-up meeting often assessing the effectiveness of revisions to intervention plans (approximating a second CTEI).

For most consultants, the cases represented in this data set were their first or second CBC cases. All interviews were audiotaped to allow for supervision and transcribing. Cases were supervised by the first author or an advanced graduate student. Data for a total of 16 cases are reported. Integrity of the CBC process was assessed by independent observers who listened to $\mathrm{CBC}$ audiotapes and recorded the number of objectives met on structured checklists. For this sample of consultants and CPIIs, the average percentage of objectives met was $92.4 \%$.

Transcription and segmenting. The consultation segments used for analyses comprised 30-minute excerpts (16 to 46 minutes) from 16 CPIIs. CPIIs were coded without the inclusion of additional CBC interviews (i.e., CPAIs, CTEIs) to aid in the manageability and interpretability of the data set and because previous research has demonstrated the representativeness of coding only these interviews 
in behavioral consultation research (Erchul \& Schulte, 1990). Specifically, the CPII-only sample yielded 8,848 codeable speech acts and 4,986 code-able speech act exchanges. Furthermore, Erchul and Schulte (1990) found that reliable and accurate estimates of interactionally defined variables were obtained by coding samples of PIIs. These authors recommended coding this interview only for purposes of efficiency and to allow comparisons with similar studies (Erchul et al., 1999; Witt, Erchul, McKee, Pardue, \& Wickstrom, 1991).

The interviews selected for analysis were drawn from a larger consultation study conducted by the first author. They were selected based on the completeness of cases at the time of analysis, including availability of a complete set of outcome data (i.e., direct behavioral observations, BIRS, GAS, CEF). The audiotaped interactions of CPIIs for these cases were transcribed verbatim by trained research assistants. Each transcript was edited by another research assistant who checked for accuracy and added important comments or symbols that facilitated understanding and coding of the interactions (e.g., interruptions, extended silences). After transcription, each transcript was segmented into speech acts. A speech act was defined as a phrase or utterance, bounded by intonation, pauses, or grammar, which conveyed a single message and could be coded into one of the four interaction coding categories (Leaper, 1991; Penman, 1980). For example, each of "Uh-huh," "Pardon me," and "His only friend is Johnny across the street," were considered single speech acts.

To assess reliability of segmenting, trained research assistants carefully listened to audiotapes of the transcribed consultation sessions, and marked and numbered speech acts directly on the transcripts. Using the second author as a criterion coder, more than $90 \%$ (range $=90 \%$ to $96 \%$ ) of research assistants' segment marks were identical to the second author (i.e., number of identical marks divided by the number of identical marks plus the number of additional or missing marks on the research assistants' transcripts). The majority of differences in segmenting concerned "lists" of information within a single speaker's turn that were coded into the same speech act category and these differences had no effect on the final proportions of speech acts within individuals. In addition, disagreements in segmenting never occurred during speaker changes and had no effect on the speech act exchanges between participants.

Four coders were trained to use the Psychosocial Processes Coding System by the second author, who has extensive expertise with this system and type of research and coded portions of the data himself. Operational definitions of the speech act categories were identical to those used in previous research, although examples used in training were modified to reflect $\mathrm{CBC}$ interactions. One-quarter of the transcripts $(n=4)$ were coded to assess interrater reliability. Across all possible combinations of coders, $\mathrm{k}$ coefficients (which control for chance agreement; see Cohen, 1960) for the four-category system averaged .79 (range $=.76$ to .88$)$.

After coding and data entry, three types of sequences of interactions were created to reflect interaction processes important to the present project. As described 
above, affiliative (high involvement) sequences included conversational exchanges between group members with collaborative or obliging speech acts. Distancing (low involvement) sequences included conversational exchanges between group members with controlling or withdrawing speech acts. Mixed sequences included mixtures of affiliative and distancing involvement.

\section{Analyses}

Given the exploratory nature of this study, speech act and speech act exchange data were analyzed descriptively. Proportion scores for each speech act and speech act exchange were computed. Speech act proportions were based on the total number of speech acts within speakers. Speech act exchange proportions were based on the total number of exchanges within a consultation triad or group (i.e., consultant, parent, teacher).

For summary purposes, effect sizes for individual (single subject) cases were computed based on behavioral data collected by teachers and parents. A "no assumptions" approach (Busk \& Serlin, 1992) that computes effects without assumptions regarding population distributions or homogeneity of variance was used. In this approach, the difference in phase means within a given case is divided by the standard deviation of the baseline, which produces a quantitative index of treatment effects. Effect sizes of +1 or more indicate that the effect size is similar to one or more standard deviation units above the expected baseline mean. Because effect sizes are calculated based on the standard deviation of the baseline phase, behaviors that experienced a great degree of baseline variability are negatively affected.

The relationship between speech act exchanges (i.e., affiliative, distancing, mixed) and outcome data was of particular interest. Pearson product moment correlations were conducted for speech act exchanges, objective and subjective outcome measures (i.e., home effect sizes, school effect sizes, parent BIRS-Effectiveness scores, teacher BIRS-Effectiveness scores, parent GAS scores, teacher GAS scores), and acceptability/satisfaction measures (i.e., parent BIRS-Acceptability scores, teacher BIRS-Acceptability scores, parent CEF scores, teacher CEF scores). Given the number of correlations computed $(n=33)$, significance levels were adjusted using the Bonferroni procedure to control for family-wise error rates. It was expected that the relationship between affiliation and case outcomes would be positive and that the relationship between distancing exchanges and case outcomes would be negative. Because the direction of results was specified in advance, one-tailed tests were conducted.

\section{RESULTS}

\section{Communication Strategies}

Data were collected on 8,848 codeable speech acts by individuals and 4,986 codeable speech act exchanges between interactants. Approximately $2 \%$ of all 
TABLE 2. Percentage of Speech Acts Across Participants by Category

\begin{tabular}{lcccc}
\hline Participant & Collaborative $(\%)$ & Controlling $(\%)$ & Obliging $(\%)$ & Withdrawing $(\%)$ \\
\hline Consultant & 66.7 & .8 & 31.5 & 1.0 \\
Teacher & 86.0 & 3.5 & 9.7 & .8 \\
Parent & 82.2 & 2.0 & 15.2 & .6 \\
\hline
\end{tabular}

TABLE 3. Proportion of Speech Act Exchanges by Category Across Cases

\begin{tabular}{lccc}
\hline Proportion & Affiliative & Distancing & Mixed \\
\hline Mean & .947 & .004 & .049 \\
$S D$ & .053 & .005 & .049 \\
Range & $.82-.99$ & $.00-.016$ & $.007-.168$ \\
\hline
\end{tabular}

Note. Data reflect proportions of speech act exchanges averaged across cases.

speech acts and $6 \%$ of speech act exchanges were inaudible and were not considered in the analyses. Table 2 presents the percentage of various speech acts made across participants (i.e., consultant, parent, teacher). The vast majority of speech acts were of an affiliative nature (i.e., collaborating or obliging); these acts represented $98.2 \%$ of consultants', $95.7 \%$ of teachers', and $97.4 \%$ of parents' comments. A negligible amount of speech acts were controlling (3.5\% or fewer) or withdrawing ( $1 \%$ or fewer of any participant's speech acts). A between-subjects analysis of variance yielded differences among participants in collaborative speech acts, $F(2,13)=11.64, p=.001$ and in obliging speech acts, $F(2,13)=21.49, p$ $=.000$. Post hoc pairwise comparisons revealed that consultants made fewer collaborative statements relative to teachers (mean absolute difference $=19.3 \%, p=$ .000 ) and parents (mean absolute difference $=15.5 \%, p=.008$ ). Consultants also made more obliging statements compared to both teachers (mean absolute difference $=21.8 \%, p=.000$ ) and parents (mean absolute difference $=16.3 \%, p=001$ ).

Table 3 depicts the proportion of speech act exchanges by category (i.e., affiliative, distancing, mixed). Consistent with the speech act unit analysis, speech act exchanges were overwhelmingly affiliative. Specifically, approximately $95 \%$ of codeable exchanges were characterized as affiliative (i.e., composed of some combination of collaborative or obliging speech acts), whereas less than $1 \%$ of exchanges were characterized as distancing and approximately $5 \%$ were mixed. The social context in these $\mathrm{CBC}$ interviews tended to reflect a highly affiliative, mutually cooperative tone.

Consultants, parents, and teachers contributed approximately equally in the consultation dialogue. Specifically, the relative proportion of total speech acts by consultants, parents, and teachers was $.40, .30$, and .30, respectively. Because relative frequency of speech acts was not of interest in this study, differences in proportion of speech acts among participants were not subjected to further analyses. 


\section{Case Outcomes}

Table 4 reports the objective (direct observations) and subjective (consultees' perceptions of efficacy) outcomes of the 16 CBC cases (i.e., effect sizes, BIRS-Effectiveness ratings, GAS scores). Table 5 reports results of $\mathrm{CBC}$ acceptability and satisfaction ratings (i.e., BIRS-Acceptability ratings, CEF).

Direct observations of behavior change. Across the 16 cases, 24 effect sizes are available (13 school; 11 home). As can be seen in Table 4, effect sizes at school averaged 1.1 (range $=.25-2.92 ; S D=.73)$. Home effect sizes averaged 1.3 (range $=-.17$ to $3.21 ; S D=.95)$. Case effects averaged 1.1 and 1.3 standard deviations above expected school and home baseline levels, respectively. Total effect size (based on the average effect size between home and school effect sizes for each case) was 1.2. These are considered very favorable effect sizes (Cohen, 1992).

Perception of efficacy. Consultees' subjective evaluations of behavior change (social validation) were assessed via the Effectiveness factor on a revised version of the BIRS (Von Brock \& Elliott, 1987). On a scale of 1 to 6 (with 1 representing low perceived efficacy and 6 representing high perceived efficacy), both teachers and parents provided mean item scores of 4.5. This suggests that both teachers and parents reported moderate effectiveness of CBC-based interventions in instilling behavioral change in the students who were the recipients of services.

Goal Attainment Scaling. Goal Attainment Scaling (GAS) procedures served as a second source of perceived effectiveness and social validation. Teachers' and parents' perceptions of the degree to which consultation goals were met were recorded on a 5-point scale, with 1 reflecting that the problem situation got significantly worse and 5 reflecting that the goal was completely met. At school and home, GAS ratings averaged 4.2 and 4.3, respectively. This reflects consul-tee perceptions that CBC-generated goals were mostly met.

TABLE 4. CBC Case Outcomes Across Objective and Subjective Measures

\begin{tabular}{|c|c|c|c|c|c|c|c|}
\hline & \multicolumn{3}{|c|}{ Effect Sizes $^{a}$} & \multicolumn{2}{|c|}{ BIRS-Effectiveness ${ }^{b}$} & \multicolumn{2}{|c|}{$\mathrm{GAS}^{c}$} \\
\hline & School & Home & Total & School & Home & School & Home \\
\hline Mean & 1.1 & 1.3 & 1.2 & 4.5 & 4.5 & 4.2 & 4.3 \\
\hline SD & .73 & .95 & .77 & 1.26 & 1.04 & .83 & .48 \\
\hline Range & $.25-2.92$ & $-.17-3.21$ & $.04-2.92$ & $2.14-6$ & $1.43-6$ & $2-5$ & $4-5$ \\
\hline
\end{tabular}

Note. ${ }^{a}$ Effect sizes (ESs) were based on direct observational data collected across baseline and treatment conditions for each case. Effect sizes are interpreted in standard deviation units; ES \$ .80 suggests significant positive change. School and home ESs reflect those obtained for school-and homebased target behaviors; total ESs are based on the average between school and home ESs for each case. ${ }^{b}$ BIRS-Effectiveness $=$ Perceived efficacy of $\mathrm{CBC}$ in addressing behavioral concerns addressed in consultation, as perceived by consultees (as assessed on the Effectiveness factor of a revision of the Behavioral Intervention Rating Scale). Scores reflect average item ratings. Possible range $=1$ to 6 , with high scores reflecting high efficacy ratings. ${ }^{c} \mathrm{GAS}=$ Social validity ratings concerning consul-tees' perceptions of the degree to which consultation goals were attained. Possible range $=1$ to 5 , with high scores reflecting perceptions that goals were met to a favorable degree. 
TABLE 5. CBC Acceptability and Satisfaction Ratings

\begin{tabular}{lccccc}
\hline & \multicolumn{2}{c}{ BIRS-Acceptability } & \multicolumn{2}{c}{ CEF $^{b}$} \\
\cline { 2 - 5 } \cline { 5 - 5 } & School & Home & & School & Home \\
\hline Mean & 5.5 & 5.3 & 76.87 & 75.31 \\
SD & .60 & .48 & 6.74 & 6.35 \\
Range & $4-6$ & $4.4-6$ & $63-84$ & $64-84$ \\
\hline
\end{tabular}

Note. ${ }^{a}$ BIRS-Acceptability $=$ Acceptability of $\mathrm{CBC}$ as perceived by consultees (as assessed on the Acceptability factor of a revision of the Behavioral Intervention Rating Scale). Scores reflect average item ratings. Possible range $=1$ to 6 , with high scores reflecting high acceptability ratings. ${ }^{b} \mathrm{CEF}=\mathrm{Satisfac}-$ tion with the consultant as measured on the Consultant Evaluation Form, on a scale of 1 to 7 , with high scores reflecting a high level of satisfaction. Total possible score $=12$ to 84 .

Acceptability and satisfaction. Acceptability of CBC services was assessed via ratings on the 15 items comprising the first factor (Acceptability) of the BIRS (Von Brock \& Elliott, 1987), revised to assess the acceptability of CBC. On a scale of 1 to 6 (with 1 representing low acceptability and 6 reflecting high acceptability), parents and teachers reported average item ratings of 5.3 and 5.5, respectively (see Table 5). Consultees found the CBC procedures to be very acceptable.

Consultees' satisfaction with the consultant was measured with the CEF (Erchul, 1987). Items on the CEF are scored on a scale of 1 to 7 , with 1 representing low satisfaction and helpfulness and 7 reflecting high satisfaction and helpfulness. Total possible scores ranged from 12 to 84. As reflected in Table 5, total scores averaged 75 for parents and 77 for teachers (average item scores of 6.25 and 6.42, respectively). This suggested that consultees found the consultants very helpful and were quite satisfied with their services.

\section{Relationship Between Speech Act Exchanges and Outcomes}

Pearson product moment correlations were computed to examine the relationship between the affiliative and distancing speech act exchanges in consultation and case outcomes (defined both objectively and subjectively). After controlling for family-wise error rates using the Bonferroni correction procedure, no significant relationships were uncovered between speech act exchanges and behavioral effect sizes at home or at school. Similarly, no significant relationships were found between speech act exchanges and subjective outcome measures.

\section{DISCUSSION}

The results of this exploratory study reveal important findings regarding the social context and relational dynamics in CBC. Compared with findings of other researchers using different methods and instruments, individual primary speech acts were found to be highly collaborative, followed in frequency by obliging. A negligible amount were controlling or withdrawing. When consultants were not 
making collaborative statements, they were making statements that were obliging and not controlling. Furthermore, the nature of interactions and the social context in these CBC samples (assessed with speech act exchanges) was overwhelmingly affiliative, characterized by a reciprocal "give and take," cooperative conversational style (e.g., collaborate-collaborate; collaborate-oblige). In addition, participants were able to maintain the structural objectives of the $\mathrm{CBC}$ interviews, as documented by the high percentage of $\mathrm{CBC}$ objectives met on the $\mathrm{CBC}$ Objectives Checklists. Participants were highly involved in maintaining task and relational aspects of the interviews. The function of the exchanges seemed to join participants together, moving the consultation process along via an affiliative, cooperative interactive style. Fewer than $1 \%$ of codeable speech act exchanges were characterized as distancing. Furthermore, very favorable effect sizes and positive subjective outcomes in the present cases were apparent, supporting contentions that participants (including consultants) can be highly affiliative and collaborative without jeopardizing behavioral outcomes for students.

The formation of positive relationships among parents and teachers (homes and schools) is central in structuring pathways for student success (Pianta, 1999; Pianta \& Walsh, 1996). The vast literature on home-school partnerships reiterates the importance of open, positive communication between family members and school personnel (Ames, 1993; Christenson \& Sheridan, 2001; Swap, 1993; Weiss \& Edwards, 1992). Conjoint behavioral consultation has been offered as a model by which partnerships between homes and schools can be fostered and constructive communications among home and school systems can be established. This study investigated the nature of communicative processes (or social context) in initial CBC interviews and found that the social context in $\mathrm{CBC}$ is one in which participants support the maintenance of the relationship (as manifested by speech act exchanges overwhelmingly high on involvement). Furthermore, in that effect sizes were meaningful and positive, it appears that CBC provides a vehicle for the establishment of positive, effective partnerships across home and school systems.

This study was among the first in the consultation-based relational communication literature to use a system that defines the collaboration construct. Many authors (Gutkin, 1999; Kratochwill, 1991; Sheridan, 1992) have suggested the need for a clear definition of collaboration. The definition used in the PPCS captured what we believe to be the essential components of the collaboration construct (i.e., speech acts that are concerned with directly influencing the consultation task while also maintaining affiliative social involvement). These include instances of mutual affirmation, constructive elaboration, initiations of joint activity, and exchanges of information (Leaper, 1991). For example, collaborative statements may have required direct bids for joint participation and activity (e.g., "Is it possible to collect information for one week?"). Thus, collaborative speech acts in this system had a directive component tied to an affiliative component. 
This is consistent with the notion that $\mathrm{CBC}$ is composed of both task (i.e., problem solution) and process (i.e., relational and interpersonal) functions. The investigation and analysis of either in isolation may actually misrepresent the complex nature and goals of CBC (Sheridan et al., 1992; Sheridan et al., 1996). Furthermore, examination of speech act exchanges that capture the interpersonal, mutual nature of consultation (i.e., involvement in the social relationship of $\mathrm{CBC}$ ) contribute a richer appraisal of the reciprocal consultation relationship.

The findings of this study also shed light on the degree to which various outcome and process goals of $\mathrm{CBC}$ are attained in practice. Outcome goals involve attaining effective behavioral change in students for which parents and teachers share concerns. Positive outcomes were achieved in these cases, as demonstrated by both objective and subjective measures. Effect sizes as reflected by direct behavioral observations suggested very strong outcomes. Social validity indices, reflected through subjective ratings of the efficacy, acceptability, and helpfulness of $\mathrm{CBC}$ also revealed very positive parent and teacher responses. CBC process goals include (a) joining home and school participants in educational problem solving; (b) engaging in constructive communications about a child; (c) increasing homeschool collaboration and partnerships; and (d) promoting shared ownership and power in decision making (Sheridan et al., 1996). The affiliative and cooperative patterns of communication demonstrated by participants in this study provide some preliminary, indirect evidence of these goals.

The current findings and interpretation of exchanges in CBC using the PPCS are consistent with some previous research. Specifically, they corroborate the findings of Erchul et al. (1999) who found that all participants were involved in CBC, with minimal differences in dominance between consultants and consul-tees. The system used by those authors investigated individual participants' demonstration of dominance relative to other participants. These authors described interactions in CBC as "reciprocal," "bi-directional," and "collaborative," descriptors with which we agree, based on our current research findings. The system used in the present study explored the social context in $\mathrm{CBC}$, which more accurately depicts consultation as an interactional process that can be interpreted only in the context of reciprocal exchanges.

Our findings are also consistent with Erchul et al. (1995), who reported that affiliative bids were significantly and positively correlated with positive responses on the CEF. Pure distancing bids by consultants were significantly and negatively related to responses on the CEF. Similar to the conclusions drawn in the present study, Erchul et al. concluded that "these data offer support for a give-and-take, cooperative interaction pattern between consultants and consul-tees" (Erchul et al., 1996, p. 626). Finally, Hughes and DeForest (1993) found that supportive consultant verbalizations correlated significantly and positively with CEF scores and the use of closed questions were negatively related to CEF scores.

The definition of collaboration used in this study and the analysis of influence 
and involvement are important. Clearly, the manner in which collaboration is defined recognizes task and social demands in consultation. The use of the PPCS reflects our belief that the collaboration construct can have a directive component (Gutkin, 1999). This is in contrast to Noell and Witt's (1996) statement that behavioral consultation and its variants "devalue any expert content knowledge . . . [and] content knowledge is unnecessary to an effective consultant" (p. 194). On the contrary, the coding system used represents various, complex dimensions of consultation and $\mathrm{CBC}$ objectives. Although no significant correlations were found between speech act exchanges and objective case outcomes, it is clear that very successful outcomes were demonstrated in the context of affiliative, cooperative CBC relationships. Indeed, it is very possible that no significant correlational findings emerged because of the highly restrictive range for speech act variables (see Table 3). The proportion of distancing and mixed speech act exchanges is substantially lower than affiliative speech act exchanges, with limited variability within each. Future research should be considered that investigates relationships between speech act exchanges and outcomes when more variance is present.

Several limitations are noteworthy in this study, limiting the generalizability of the findings. First, it is important to reiterate that this study was exploratory by design. It represents a first attempt to understand the relationship between collaborative and affiliative communication patterns in $\mathrm{CBC}$ and objective case outcomes. No control was exerted to explore the relationships or differences among participants experimentally. Furthermore, no investigation of important intermediary variables (e.g., nature, severity, or history of target behavior; personal resources available to consultees; acceptability of intervention plan; integrity with which the plan was delivered by parents or teachers; classroom or home environmental contingencies) was conducted. It is possible that speech acts are not directly related to outcomes but are influenced by known or unknown mediating variables. It is also possible, however, that variables such as treatment implementation are mediated by the nature and tone of interactions among participants in $\mathrm{CBC}$ interviews. For example, parents enjoying a more mutual, constructive, and active role in $\mathrm{CBC}$ interviews may be more likely to deliver treatments at home and may feel more efficacious in their role as treatment implementer. Future research may investigate direct and indirect links between communication exchanges, intermediary variables, and behavioral outcomes in $\mathrm{CBC}$, and begin to understand such relationships empirically.

An important limitation of this study was that the findings were based on a somewhat limited sample. The total number of cases that formed the basis of the analyses was 16, although several thousand speech acts and exchanges were examined. All consultants were trained by the same researcher and were influenced by one conceptualization of $\mathrm{CBC}$ practice. Thus, the generalizability of findings beyond this sample is suspect and influenced by the training and supervision provided by the first author. It is possible that field-based consultants, or those trained by someone espousing a different philosophy of consultation practice, may per- 
form differently and, therefore, promote a different interpersonal climate (i.e., social context) in $\mathrm{CBC}$ interviews.

A third limitation concerns the lack of reliability data for direct behavioral outcomes. Parents and teachers provided the outcome data when direct observations were required; permanent product data were examined when possible (e.g., academic assignments resulting in worksheets). Although efforts were made by consultants to prepare consultees for the task of reporting behaviors objectively, there is no assurance that the behavioral data are completely accurate. Given the scope of the project in which this sample of data was derived, systematic independent observations at home and at school were not possible. Future research should identify ways to conduct unobtrusive observations across home and school settings to yield clear behavioral data for a larger sample.

Fourth, only Conjoint Problem Identification Interviews (CPIIs) were coded for purposes of these analyses. These were chosen based on the empirical suggestion of Erchul and Schulte (1990); however, it is possible that unique interpersonal dynamics associated with later $\mathrm{CBC}$ interviews were missed. For example, time spent in contact with one another or specific task objectives of Conjoint Problem Analysis Interviews (CPAIs) and Conjoint Treatment Evaluation Interviews (CTEIs) may have influenced the level of influence or involvement of participants. If the nature of the social exchanges was found to differ across interviews given differential task demands, the correlations with various CBC outcomes may be affected and additional research directions uncovered. The results of the present study must be considered reflective of only the social exchanges in initial interviews. Research focused on $\mathrm{CBC}$ interactions over time, using the PPCS, may be warranted.

The cases represented in this study were a subset of a larger research project for which the first author was principal investigator. These cases were selected because they had complete data available (i.e., demographic information, behavioral outcome data, subjective perceptions of outcome). Relatedly, there is no way of ensuring that consultees reported their accurate perceptions on the paper-and-pencil instruments, rather than responses that were desirable in nature. This sample represents a select group of participants who completed all the forms and provided a full set of data to the researchers. This procedure was imposed to ensure that correlational analyses could be conducted on the complete sample, rather than a smaller subset of an already limited number of cases. However, it is recognized that the decision to include only these participants could have imposed a sampling bias. The willingness of these participants to complete forms and provide requested data may reflect a sample inclined toward involvement and cooperation and speech styles that are highly involved and affiliative. This clearly limits the generalization of the findings to cases that yield behavioral data and to parents and teachers who complete forms reporting subjective perceptions of outcomes and services.

Several additional directions for future research are highlighted in this exploratory analysis. To further the relational communication research in the consultation 
context, it is imperative that researchers begin examining experimentally whether indices of speech acts are the mechanism through which consultee perceptions are based. Assumptions are made that the relational styles illuminated in the analyses are causally related to participants' subjective reactions; however, no direct links can be determined. The relationship between speech act exchanges and behavioral case outcomes is indirect. There are likely intermediary variables that limit the ability of researchers to investigate the relationship of conversational patterns in $\mathrm{CBC}$ and behavioral outcomes.

Approximately $4 \%$ of speech exchanges were mixed. Although this was negligible in the scheme of the entire dataset, some individual case differences were noted. The range of proportions revealed that in some cases $(n=2)$ up to $16 \%$ of exchanges were of the mixed type. These may prove interesting in their own right. For example, some mixed exchanges may reflect efforts of one party to mediate a distancing comment with one that is affiliative in nature. This would reflect an effort to maintain the relationship among CBC participants. However, it is possible that the reverse may be true; mixed exchanges could comprise an affiliative comment followed by one that is more distancing. In this case, the "bid" for affiliation (joining participants in the relationship) would not be accepted by an interactant. Qualitative research is needed to explore cases where mixed exchanges are prevalent, investigating characteristics of participants, speech patterns within and among individuals, and other interpersonal and relational variables.

In practice, several additional interactions typically occur between consultants and consultees beyond the formal interviews, such as preconsultation meetings, checks on data collection and treatment implementation, opportunities for immediate troubleshooting, and other overtures of support. Although the structured $\mathrm{CBC}$ interviews represent the primary mechanism for the problem-solving task, it is possible that the consultative relationship is formed as a result of these and other more global, informal interactions. These latter interpersonal exchanges are not captured on audiotaped interviews and their influence in the development of consultee perceptions is unknown. Similarly, caution must be exercised when attempting to discern relationships between interpersonal exchanges and objective behavioral outcomes. Research is needed to explore and identify which of a host of mediating variables may affect these relationships.

Erchul (1999) stated that, "It will be easier to reach consensus and resolution in the collaboration 'debate' when discussion centers on operational definitions and conclusions that are anchored to observable phenomena" (p. 194). Using a system that directly defines and measures collaborative statements and related exchanges, we believe that this study advances our understanding of the constructs in consultation practice. The outcomes of this exploratory study suggest that behavioral consultants can be direct and affiliative at the same time, which is characterized as "collaborative" in this context. Very strong and positive effect sizes were apparent in these cases, supporting the contention that CBC consultants can facilitate effective case outcomes while engaging in collaborative interactions and behaving in 
affiliative ways. All participants (i.e., consultants, parents, teachers) were highly active and influential in the CBC process. Thus, the need to "control" or "dominate" $\mathrm{CBC}$ interactions seems unsubstantiated by the current exploratory analyses.

\section{REFERENCES}

Ames, C. (1993). How school-to-home communications influence parent beliefs and perceptions. Equity and Choice, 9, 44-49.

Azmitia, M. (1996). Peer interactive minds: Developmental, theoretical, and methodological issues. In P. B. Baltes \& U. M. Staudinger (Eds.), Interactive minds: Lifespan perspectives on the social foundation of cognition (pp. 133-162). New York: Cambridge University Press.

Babcock, N. L., \& Pryzwansky, W. B. (1983). Models of consultation: Preferences of educational professionals at five stages of service. Journal of School Psychology, 21, 359366.

Berg, C. A., Meegan, S. P., \& Deviney, F. P. (1998). A social-contextual model of coping with everyday problems across the life span. International Journal of Behavioral Development, 22, 239-261.

Berg, C. A., Johnson, M. M. S., Meegan, S. P., \& Strough, J. (in press). Collaborative problem-solving interactions in young and old married couples. Discourse Processes.

Bergan, J. R., \& Tombari, M. L. (1975). The analysis of verbal interactions occurring during consultation. Journal of School Psychology, 13, 209-226.

Bergan, J. R., \& Tombari, M. L. (1976). Consultant skill and efficiency and the implementation of outcomes of consultation. Journal of School Psychology, 14, 3-14.

Busse, R. T., Kratochwill, T. R., \& Elliott, S. N. (1999). Influences of verbal interactions during behavioral consultations on treatment outcomes. Journal of School Psychology, 37, 117-143.

Busk, P. L., \& Serlin, R. C. (1992). Meta-analysis for single-case research. In T. R. Kratochwill \& J. R. Levin (Eds.), Single-case research design and analysis: Applications in psychology and education (pp. 187-212). Mahwah, NJ: Erlbaum.

Cardillo, J. E., \& Smith, A. (1994). Reliability of goal attainment scores. In T. J. Kiresuk, A. Smith, \& J. E. Cardillo (Eds.), Goal attainment scaling: Applications, theory, and measurement (pp. 213-242). Mahwah, NJ: Erlbaum.

Christenson, S. L., \& Sheridan, S. M. (2001). Schools and families: Creating essential connections for learning. New York: Guilford.

Cohen, J. (1960). A coefficient for agreement for nominal scales. Educational and Psychological Measurement, 20, 37-46.

Cohen, J. (1992). A power primer. Psychological Bulletin, 112, 155-159.

Colton, D., \& Sheridan, S. M. (1998). Conjoint behavioral consultation and social skills training: Enhancing the play behavior of boys with attention deficit-hyperactivity disorder. Journal of Educational and Psychological Consultation, 9, 3-28.

Elliott, S. N., \& Von Brock Treuting, M. (1991). The Behavior Intervention Rating Scale: Development and validation of a pretreatment acceptability and effectiveness measure. Journal of School Psychology, 29, 43-51. 
Erchul, W. P. (1987). A relational communication analysis of control in school consultation. Professional School Psychology, 2, 113-124.

Erchul, W. P. (1999). Two steps forward, one step back: Collaboration in school-based consultation. Journal of School Psychology, 37, 191-203.

Erchul, W. P., Covington, C. G., Hughes, J. N., \& Meyers, J. (1995). Further explorations of request-centered relational communication within school consultation. School Psychology Review, 24, 621-632.

Erchul, W. P., \& Schulte, A.C. (1990). The coding of consultation verbalizations: How much is enough? School Psychology Quarterly, 5, 256-264.

Erchul, W. P., Sheridan, S. M., Ryan, D. A., Grissom, P. F., Killough, C. E., \& Mettler, D. W. (1999). Patterns of relational control in conjoint behavioral consultation. School Psychology Quarterly, 14, 121-147.

Folger, J. P., \& Puck, S. (1976). Coding relational communication: A question approach. (Available from the Department of Communication, University of Utah, $255 \mathrm{~S}$. Central Campus Drive, Salt Lake City, UT 84112.)

Friend, M., \& Cook, L. (1992). Interactions: Collaboration skills for school professionals. New York: Longman.

Fuchs, D., \& Fuchs, L. S. (1989). Exploring effective and efficient prereferral interventions: A component analysis of behavioral consultation. School Psychology Review, 18, 260-283.

Galloway, J., \& Sheridan, S. M. (1994). Implementing scientific practices through case studies: Examples using home-school interventions and consultation. Journal of School Psychology, 32, 385-413.

Gutkin, T. B. (1980). Teacher perceptions of consultation services provided by school psychologists. Professional Psychology: Research \& Practice, 11, 637-642.

Gutkin, T. B. (1999). Collaborative versus directive/prescriptive/expert school-based consultation: Reviewing and resolving a false dichotomy. Journal of School Psychology, 37, 161-190.

Gutkin, T. B., \& Curtis, M. J. (1982). School-based consultation: Theory and techniques. In C. R. Reynolds \& T. B. Gutkin (Eds.), The handbook of school psychology (pp. 796828). New York: Wiley.

Hughes, J. N., \& DeForest, P. A. (1993). Consultant directiveness and support as predictors of consultation outcomes. Journal of School Psychology, 31, 355-373.

Jacobs, S., \& Cytrynbaum, S. (1977). The goal attainment scale: A test of its use on an inpatient crisis intervention unit. Goal Attainment Review, 3, 77-98.

Johnson, S. M., \& Greenberg, L. S. (1985). Differential effects of experiential and problemsolving interventions in resolving marital conflict. Journal of Consulting and Clinical Psychology, 53, 175-184.

Johnson, D. W., Maruyama, G., Johnson, R., Nelson, D., \& Skon, L. (1981). Effects of cooperative competitive, and individualistic goal structures on achievement: A meta-analysis. Psychological Bulletin, 89, 47-62.

Kaplan, J. M., \& Smith, W. G. (1977). The use of attainment scaling in the evaluation of a regional mental health program. Community Mental Health Journal, 13, 188-193.

Kazdin, A. E. (1977). Assessing the clinical or applied importance of behavior change through social validation. Behavior Modification, 1, 427-452.

Kirusek, T. J., Smith, A., \& Cardillo, J. E. (Eds.). (1994). Goal attainment scaling: Applications, theory, and measurement. New York: Erlbaum. 
Kratochwill, T. R. (1991). Defining constructs in consultation research: An important agenda in the 1990s. Journal of Educational and Psychological Consultation, 2, 291-294.

Kratochwill, T. R., Sheridan, S. M., Carrington Rotto, P., \& Salmon, D. (1991). Preparation of school psychologists to serve as consultants for teachers of emotionally disturbed children. School Psychology Review, 20, 530-549.

Leaper, C. (1991). Influence and involvement in children's discourse: Age, gender, and partner effects. Child Development, 62, 797-811.

Maitland, R. E., Fine, M. J., \& Tracy, D. B. (1985). The effects of an interpersonally based problem-solving process on consultation outcomes. Journal of School Psychology, 23, $337-345$.

Maltz, D. N., \& Borker, R. A. (1982). A cultural approach to male-female miscommunication. In J. Gumperz (Ed.), Language and social identity (pp. 196-216). Cambridge, UK: Cambridge University Press.

McLeod, I. A., Jones, K. M., Somers, C. L., \& Havey, J. M. (2001). An evaluation of the effectiveness of school-based behavioral consultation. Journal of Educational and Psychological Consultation, 12, 203-216.

Meegan, S. P., \& Berg, C. A. (2002). Contexts, functions, forms, and processes of collaborative everyday problem solving in older adulthood. International Journal of Behavioral Development, 26, 6-15.

Nakamura, C. Y., \& Finck, D. N. (1980). Relative effectiveness of socially and task oriented children and predictability of their behaviors. Monographs of the Society for Research in Child Development, 45.

Noell, G. H., \& Witt, J. C. (1996). A critical evaluation of five fundamental assumptions underlying behavioral consultation. School Psychology Quarterly, 11, 189-203.

Penman, R. A. (1980). Communication processes and relationships. London: Academic Press.

Pianta, R. C. (1999). Enhancing relationships between children and teachers. New York: American Psychological Association.

Pianta, R., \& Walsh, D. B. (1996). High risk children in schools: Constructing sustaining relationships. New York: Routledge.

Rogers, L. E., \& Farace, R. V. (1975). Analysis of relational communication in dyads: New measurement procedures. Human Communication Research, 1, 222-239.

Rogoff, B. (1998). Cognition as a collaborative process. In R. S. Siegler \& D. Kuhn (Eds.), Cognitive, language, and perceptual development: Vol. 2 (pp. 679-744). In B. Damon (Gen. Ed.), Handbook of child psychology. New York: Wiley.

Schippits, H., \& Baxter, J. W. (1978). Tightening the hitch: An update on "hitch your treatment to a goal." Paper presented at Adult Psychiatric Day Treatment: 2nd Multi-Disciplinary National Forum, Minneapolis, MN.

Sheridan, S. M. (1992). What do we mean when we say 'collaboration?' Journal of Educational and Psychological Consultation, 3, 89-92.

Sheridan, S. M., Eagle, J. W., Cowan, R. J., \& Mickelson, W. (2001). The effects of conjoint behavioral consultation: Results of a 4-year investigation. Journal of School Psychology, 39, 361-385.

Sheridan, S. M., Kratochwill, T. R., \& Bergan, J. R. (1996). Conjoint behavioral consultation: A procedural manual. New York: Plenum.

Sheridan, S. M., Kratochwill, T. R., \& Elliott, S. N. (1990). Behavioral consultation with parents and teachers: Delivering treatment for socially withdrawn children at home and school. School Psychology Review, 19, 33-52. 
Sheridan, S. M., Salmon, D., Kratochwill, T. R., \& Carrington Rotto, P. J. (1992). A conceptual model for the expansion of behavioral consultation training. Journal of Educational and Psychological Consultation, 3, 193-218.

Sheridan, S. M., Welch, M., \& Orme, S. F. (1996). Is consultation effective? A review of outcome research. Remedial \& Special Education, 17, 341-354.

Smith, A., \& Cardillo, J. E. (1994). Perspectives on validity. In T. J. Kiresuk, A. Smith, \& J. E. Cardillo (Eds.), Goal attainment scaling: Applications, theory, and measurement (pp. 243-272). Mahwah, NJ: Erlbaum.

Strough, J., \& Berg, C. A. (2000). Goals as a mediator of gender differences in high-affiliation dyadic conversations. Developmental Psychology, 36, 117-125.

Strough, J., Berg, C. A., \& Meegan, S. P. (2001). Friendship and gender differences in task and social interpretations of peer collaborative problem solving. Social Development, $10,1-32$.

Swap, S. M. (1993). Developing home-school partnerships: From concepts to practice. New York: Teachers College Press.

Thorne, B. (1993). Gender play: Girls and boys in school. New Brunswick, NJ: Rutgers University.

Tracey, T. J., \& Ray, P. B. (1984). Stages of successful time-limited counseling: An interactional examination. Journal of Counseling Psychology, 31, 13-27.

Von Brock, M. B., \& Elliott, S. N. (1987). Influence of treatment effectiveness information on the acceptability of classroom interventions. Journal of School Psychology, 25, 131-144.

Merriam-Webster's new collegiate dictionary. (1981). Springfield, MA: Merriam-Webster.

Weiner, R., Sheridan, S. M., \& Jenson, W. R. (1998). Effects of conjoint behavioral consultation and a structured homework program on math completion and accuracy in junior high students. School Psychology Quarterly, 13, 281-309.

Weiss, H. M., \& Edwards, M. E. (1992). The family-school collaboration project: Systemic interventions for school improvement. In S. L. Christenson \& J. C. Conoley (Eds.), Home-school collaboration: Enhancing children's academic and social competence (pp. 215-243). Silver Spring, MD: National Association of School Psychologists.

Welch, M., \& Sheridan, S. M. (1995). Educational partnerships: Serving students at risk. San Antonio: Harcourt Brace.

Witt, J. C. (1990). Collaboration: A myth in need of data. Journal of Educational and Psychological Consultation, 1, 367-370.

Witt, J. C., Erchul, W. P., McKee, W. T., Pardue, M. M., \& Wickstrom, K. F. (1991). Conversational control in school-based consultation: The relationship between consultant and consultee topic determination and consultation outcome. Journal of Educational and Psychological Consultation, 2, 101-116.

Witt, J. C., Gresham, F. M., \& Noell, G. H. (1996). What's behavioral about behavioral consultation? Journal of Educational and Psychological Consultation, 7, 327-344.

Woodward, C. A., Santa-Barbara, J., Levin, S., \& Epstein, N. (1978). The role of Goal Attainment Scaling in evaluating family therapy outcome. American Journal of Orthopsychiatry, 48, 464-476. 